\title{
Experimental Allergic Encephalomyelitis in Cynomolgus Monkeys Quantitation of T Cell Responses in Peripheral Blood
}

\author{
L. Massacesi, N. Joshi, D. Lee-Parritz, * A. Rombos, N. L. Letvin, * and S. L. Hauser \\ Department of Neurology, Massachusetts General Hospital, Boston, Massachusetts 02114; and \\ *New England Regional Primate Research Center, Southborough, Massachusetts 01772
}

\begin{abstract}
Chronic relapsing-remitting experimental allergic encephalomyelitis (EAE) was induced in cynomolgus monkeys by a single immunization with a homogenate of human brain white matter (BH) in adjuvant. Proliferative T lymphocyte responses to $\mathrm{BH}$, to myelin basic protein (MBP), but not to proteolipid protein, were detected in peripheral blood mononuclear cells (PBMC) of all animals and persisted until their death or, in surviving animals, for $>10$ mo postimmunization. Responses of higher magnitude tended to be associated with fatal, compared with nonfatal, episodes of clinical EAE. The frequency of MBP-reactive $T$ cells in PBMC of animals with acute EAE was quantitated with a soft agar colony system; the ratio of $T$ cells that proliferated specifically to MBP was estimated at between 5 and 20 per $10^{6}$ PBMC. A similar frequency of peptide-specific $T$ cells was estimated from PBMC of monkeys immunized with a synthetic 14-mer peptide corresponding to a region near the carboxy terminus of MBP. Thus, autoantigen-reactive T cells can be detected in the circulation throughout the course of chronic EAE, are predictive of disease severity, and occur at a frequency similar to that estimated to be present in humans with multiple sclerosis. (J. Clin. Invest. 1992. 90:399-404.) Key words: experimental allergic encephalomyelitis • multiple sclerosis $\bullet$ myelin basic protein
\end{abstract}

\section{Introduction}

Experimental allergic encephalomyelitis (EAE) ${ }^{1}$ is an autoimmune disease of the central nervous system (CNS) that is mediated, in most species studied, by $\mathrm{T}$ cells reactive with myelin basic protein (MBP) $(1,2)$. Because of pathologic similarities between EAE and the human demyelinating disease, multiple sclerosis (MS), EAE has long served as a model system for testing of potential new therapies for MS patients. Trials in EAE have for the most part relied upon clinical end points (e.g., severity of paralysis) in the assessment of disease severity

Address reprint requests to Dr. Hauser, Neuroimmunology Unit, Warren 324, Massachusetts General Hospital, Boston, MA 02114.

Received for publication 20 September 1991 and in revised form 9 January 1992.

1. Abbreviations used in this paper: $\mathrm{BH}$, human brain white matter homogenate; CFA, complete Freund's adjuvant; CSF, cerebrospinal fluid; EAE, experimental allergic encephalomyelitis; MBP, myelin basic protein; MS, multiple sclerosis; PLP, phospholipid protein.

J. Clin. Invest.

(c) The American Society for Clinical Investigation, Inc.

0021-9738/92/09/0399/06 \$2.00

Volume 90, August 1992, 399-404
(3). Other proposed markers of the EAE process, for example, the quantitation of CNS inflammation (4-6) or the measurement of various nonspecific immune parameters $(7,8)$, have not gained widespread use. Some markers correlate poorly with the clinical illness score (4-6) and may require sacrifice of the subjects. These limitations are particularly evident in studies of chronic relapsing-remitting EAE, the most appropriate model system for human MS (9).

The current experiments were designed to assess the hypothesis that antigen-specific immune responses measured in peripheral blood provide an informative marker of the EAE process. Antigen reactivity from lymph node and splenic $T$ cells has been studied extensively in EAE, whereas little is known of the $T$ cell response by peripheral blood mononuclear cells (PBMC). By contrast, in humans with MS, PBMC responses have been characterized in detail. In particular, recent studies indicate that some PBMC responses to MBP are characteristic of MS (10-14); for example, a high frequency of reactive cells (12) or the preferential recognition of certain MBP epitopes (14) may be present.

Chronic relapsing-remitting EAE has been described in nonhuman primates (15-19), and these species are particularly attractive as MS models because of their close phylogeneic relationship to humans, their large size, and their outbred characteristics. We describe in this report an improved model of EAE in the cynomolgus monkey. Relapsing-remitting disease can be induced in some animals with only one injection and in the absence of corticosteroid treatment $(16,18)$. We demonstrate that PBMC T cell responses correlate with disease severity. Furthermore, we find that the frequency of $P B M C$ reactive to MBP in EAE is similar to that described in some patients with MS (12). Thus, in a chronic organ-specific autoimmune disease, PBMC responses reflect disease severity, and their measurement provides a quantitative marker of the underlying autoimmune state.

\section{Methods}

Induction of EAE in Macaca fascicularis. Macaca fascicularis were maintained in the New England Regional Primate Research Center colonies. The animals used in this study were cared for in accordance with the guidelines of the Committee on Animals of the Harvard Medical School and those of the Committee on Care and Use of Laboratory Animals of the Institute of Laboratory Animal Resources, National Research Council. A maximum of $10 \mathrm{ml}$ of blood every other week or 1 $\mathrm{ml}$ of cerebrospinal fluid (CSF) obtained by lumbar puncture on two occasions was taken from each animal.

A total of 18 animals were immunized with $200 \mathrm{mg}$ of fresh-frozen postmortem human brain white matter homogenate $(\mathrm{BH})$ emulsified with complete Freund's adjuvant (CFA) containing killed Mycobacterium tuberculosis ( $\mathrm{H} 37 \mathrm{Ra}$ strain, $3 \mathrm{mg} / \mathrm{ml}$ ). Intradermal injections (total volume of $0.5 \mathrm{ml}$ per animal) were divided in four sites on the dorsal axillary and inguinal region. Three of these animals were preimmunized with a synthetic 14-mer peptide corresponding to a region 
near the carboxyl terminus (e.g., amino acids 156-169) of MBP, in either CFA/H37Ra or incomplete Freund's adjuvant supplemented with muramyl dipeptide $(2 \mu \mathrm{g})$; EAE was induced in these animals by immunization with $\mathrm{BH} / \mathrm{CFA}-\mathrm{H} 37 \mathrm{Ra}$.

Many animals developed injection site ulcerations 2-5 wk postimmunization. In these cases, cephalexin $(20 \mathrm{mg} / \mathrm{kg}$ twice daily for $10 \mathrm{~d})$ was administered intramuscularly to prevent secondary infection.

Clinical scoring of EAE. Animals were observed daily for signs of disease. The following scoring system was employed to categorize the disease state:

\begin{tabular}{cl}
\hline Score & \multicolumn{1}{c}{ Clinical state } \\
\hline 0 & Normal neurological exam \\
1 & Lethargy, anorexia, weight loss \\
2 & Ataxia, tremor \\
3 & Blindness, paraplegia, hemiplegia \\
4 & Quadriplegia, quadriparesis \\
5 & Moribund \\
\hline
\end{tabular}

Proliferation studies. PBMC were prepared from heparinized venous blood within $3 \mathrm{~h}$ of venipuncture by density gradient centrifugation using dextran diatrizoate $(d 1,080) . \operatorname{PBMC}\left(2 \times 10^{5}\right.$ per well $)$ were cultured in a total volume of $200 \mu \mathrm{l}$ in round-bottom microtiter plates (Falcon Plastics Oxnard, CA) in culture medium consisting of RPMI 1640 supplemented with $10 \%$ Controlled Processed Serum Replacement-2 (Sigma Pharmaceuticals, St. Louis, MO), 100 mM L-glutamine (Gibco Laboratories, Grand Island, NY), $25 \mathrm{mM}$ Hepes buffer (Sigma), and $0.1 \%$ penicillin-streptomycin (Gibco). To some wells the following antigens (final concentration) were added: $(a)$ human MBP $(50 \mu \mathrm{g} / \mathrm{ml})$ prepared by the method of Deibler et al. $(20) ;(b)$ human phospholipid protein (PLP) apoprotein $(10 \mu \mathrm{g} / \mathrm{ml})$, prepared by the method of Lees and Sakur $(21) ;(c)$ human BH, $0.1 \%$, sonicated and irradiated; $(d)$ a synthetic 14-mer peptide corresponding to the region 156-169 (FKLGGRDSRGGSPM) of human MBP $(100 \mu \mathrm{g} / \mathrm{ml}) ;(e)$ concanavalin A (ConA) $(4 \mu \mathrm{g} / \mathrm{ml})$ (Sigma); $(f)$ phytohemagglutinin (PHA; $4 \mu \mathrm{g} / \mathrm{ml}$ ) (Sigma). After $5 \mathrm{~d}$ of incubation, $\left[{ }^{3} \mathrm{H}\right]$ thymidine ( 1 $\mu \mathrm{Ci} / \mathrm{ml}$ ) was added for another $16 \mathrm{~h}$, cells were harvested, and thymidine incorporation measured in a scintillation counter. Proliferative responses were expressed as stimulation indexes, defined as the stimulated culture counts per minute per unstimulated culture counts per minute in triplicate wells.

Soft agar colony quantitation of antigen-reactive $T$ lymphocytes. This method was modified from Sredni et al. (22). PBMC $\left(2 \times 10^{6} \%\right.$ $\mathrm{ml}$ ) were cultured for $3 \mathrm{~d}$ in medium supplemented with $10 \%$ human $\mathrm{AB}$ serum in the presence or absence of $\operatorname{MBP}(50 \mu \mathrm{g} / \mathrm{ml})$. Cells were then pelleted and resuspended in medium supplemented with $20 \%$ human $\mathrm{AB}$ serum, agar was added $(0.32 \%$ final concentration) in flat bottom wells, and the suspension was overlaid on a second layer of agar $(0.5 \%)$ containing medium supplemented with $20 \%$ human AB serum and $50 \mu \mathrm{g} / \mathrm{ml} \mathrm{MBP}$. The number of colonies were counted under blinded conditions between 6 and $11 \mathrm{~d}$ later using an inverted microscope. The number of MBP-specific colonies was estimated by subtraction of the number of colonies in the MBP from those in control wells.

\section{Results}

Clinical EAE in cynomolgus monkeys. Signs of EAE developed in all 15 animals immunized with BH. The clinical course took the form of an acute progressive illness leading to death within $6-12 \mathrm{~d}(n=11)$ or to complete recovery followed by the development of a relapsing-remitting chronic disease $(n=4)$. The time of onset of the initial illness ranged from day 17 to day 55 after immunization. Attacks of EAE accompanied by a clinical score of 4 or greater were invariably associated with a fatal outcome. No difference in the degree of CSF pleocytosis differentiated fatal from nonfatal attacks (Table I).

In the four animals that survived the initial attack of EAE, late relapses, numbering 1-6, occurred in all cases. These relapses resulted in death in two animals; two late survivors (> 10 mo postimmunization) remain. One long-term survivor had a single relapse of $14 \mathrm{~d}$ duration followed by complete clinical recovery. One animal developed five relapses of variable duration followed by complete recovery. One animal became permanently blind $272 \mathrm{~d}$ postimmunization. Most animals achieved complete clinical neurologic recovery after relapses that did not result in death. Fig. 1 summarizes the clinical characteristics of EAE in six representative animals.

Several clinical syndromes seen in these monkeys resembled those present in human demyelinating disorders. These included bilateral optic neuritis with marked visual disability but preserved strength and coordination; pure ataxia, acute vomiting, and instability of gait; and progressive myelopathy evolving over several days.

Sensitization to EAE by MBP 156-169. Three animals were preimmunized with a synthetic peptide corresponding to the 156-169 carboxy-terminal region of MBP. No signs of EAE were noted during a 14-mo period of observation. These animals were then immunized with BH/CFA. As shown in Fig. 2, clinical signs developed in this group between 9 and $11 \mathrm{~d}$ after immunization, compared to with onset no earlier than day 17 in the animals not preimmunized in this manner. The clinical course in peptide preimmunized animals was otherwise identical to that seen in nonpreimmunized animals: either a progressive syndrome leading to death $(n=2)$ or a relapsing-remitting course $(n=1)$.

Proliferative responses to brain antigens. PBMC proliferative responses to $\mathrm{BH}, \mathrm{MBP}, \mathrm{PLP}$, and mitogen (Con A or PHA) were assessed prospectively. As illustrated in Fig. 1 for six representative animals, proliferative responses to $\mathrm{BH}$ and to MBP were typically absent before immunization and in the early postimmunization period, but became positive at the onset of clinical signs of EAE. In animals with chronic, relapsingremitting EAE (Fig. 1, lower panels), positive PBMC responses to $\mathrm{BH}$ and MBP, once present, persisted for the duration of study, up to 10 mo postimmunization. Stimulation indexes in chronic EAE were low, generally $<10$ times background values. In both acute and chronic EAE, proliferative responses to PLP were generally low or undetectable, although an occasional animal did mount a detectible PLP-specific response (Fig. 1, bottom right).

Table I. Stimulation Index Correlations

\begin{tabular}{lccr}
\hline & \multicolumn{2}{c}{ PBMC stimulation index } & \\
\cline { 2 - 3 } & BH & MBP & CSF \\
\hline Nonfatal attacks & $6.3 \pm 2.1$ & $5.7 \pm 1.5$ & cells $/ \mathrm{mm}^{3}$ \\
Fatal attacks & $(n=15)$ & $(n=16)$ & $307 \pm 122$ \\
& $13.0 \pm 3.6$ & $8.2 \pm 3.4$ & $(n=7)$ \\
& $(n=8)^{*}$ & $(n=8)$ & $352 \pm 158$ \\
& & & $(n=7)$ \\
\hline
\end{tabular}

${ }^{*} P=0.08$, nonfatal vs. fatal attacks. 

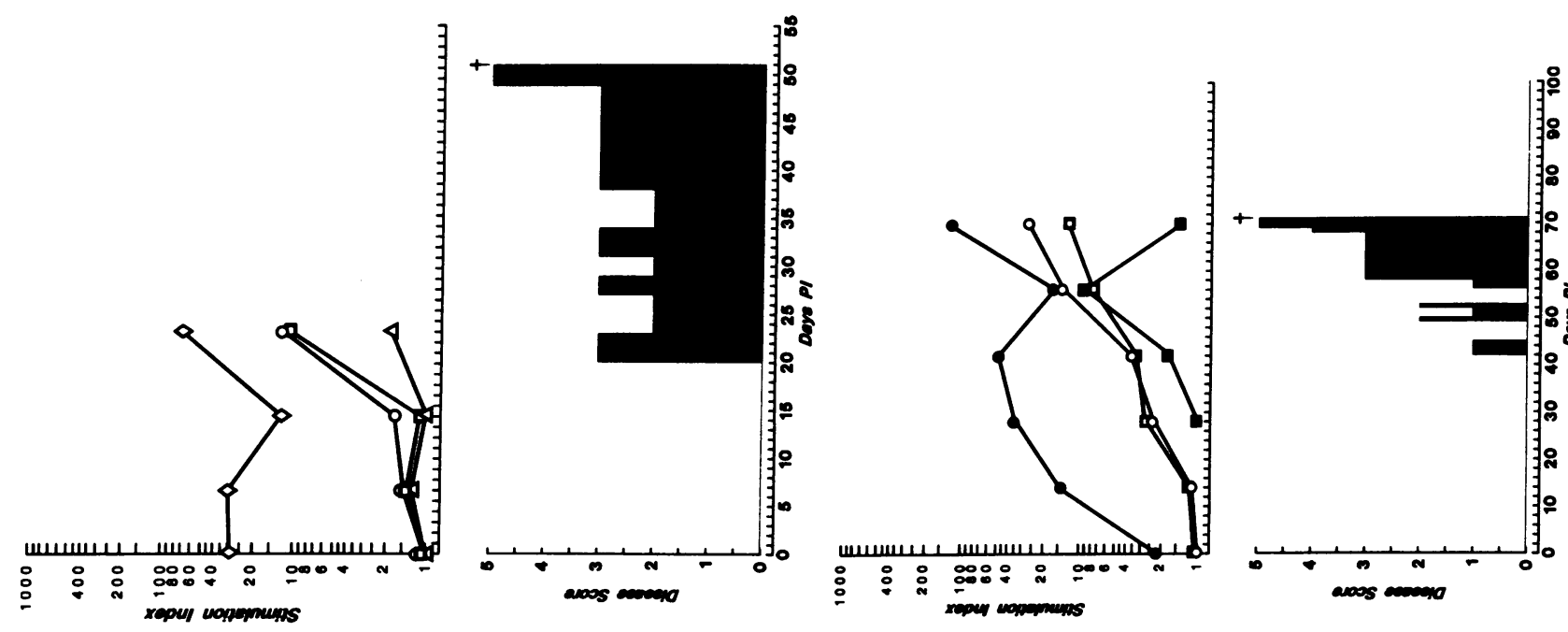

.

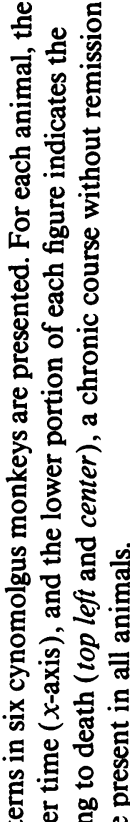
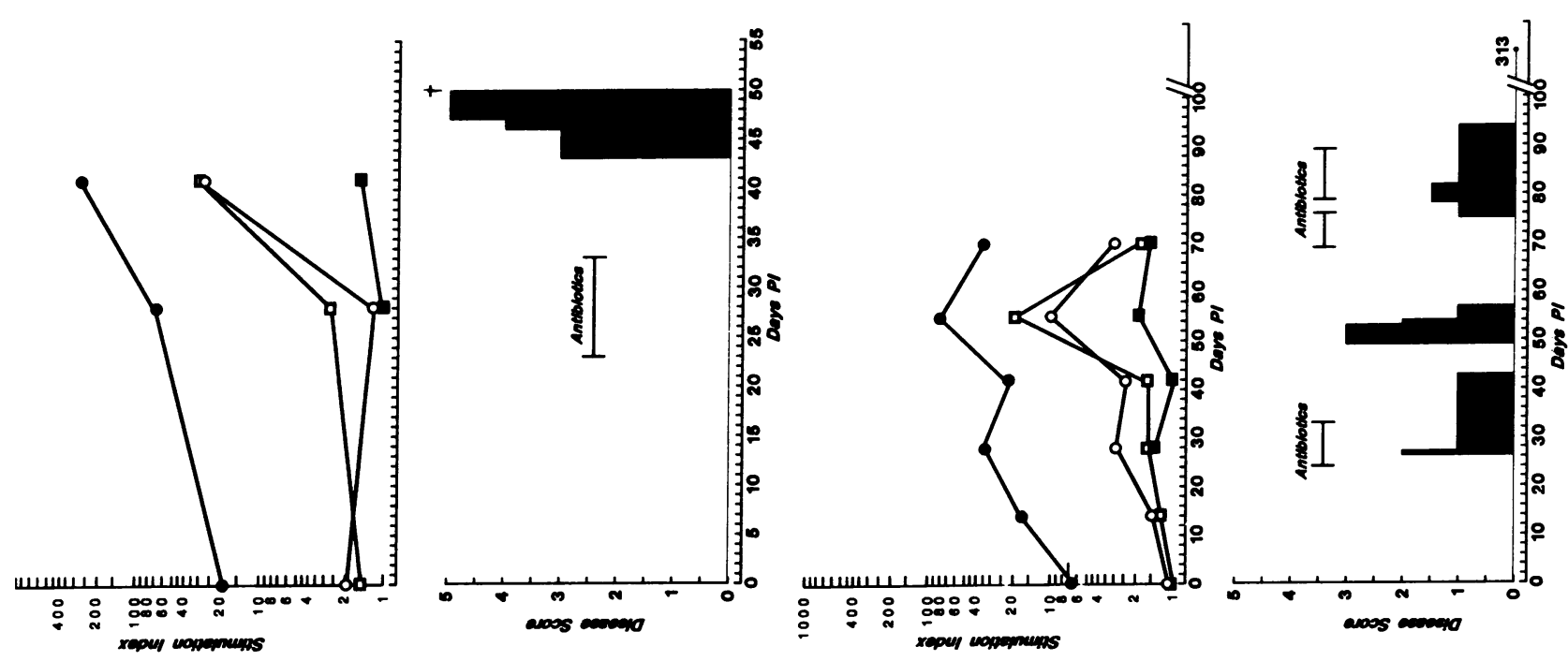

충형

高要

胥主吉

峞

응.

ส

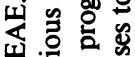

要

速

ठิ

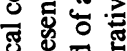

㤩绨

\&

월

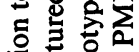

ฮั

I

通出政

论

的
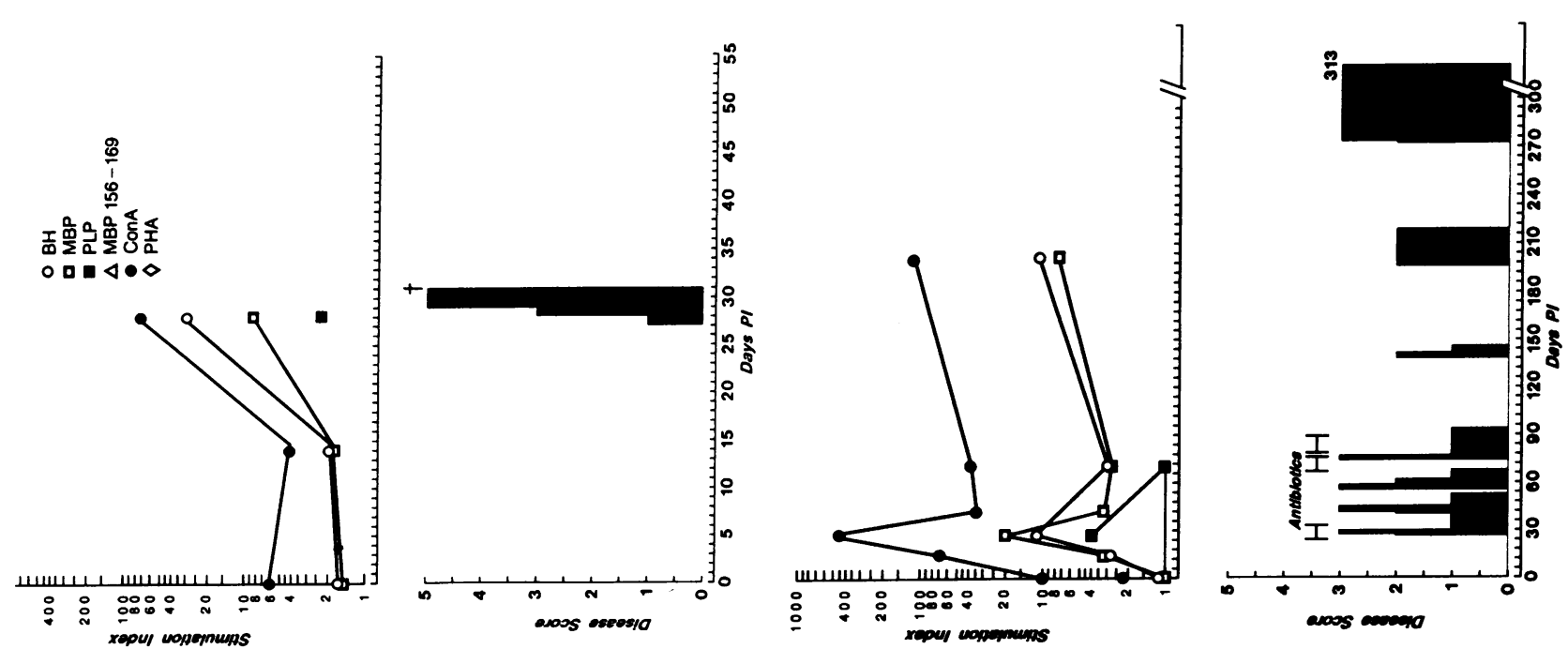

蛋.

흔 졸윻

늘

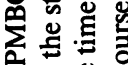

ᄂ

芯芯芯

㤐突

边

ส

홀

可

형형

항

今

ํㅔㅇㅢ 

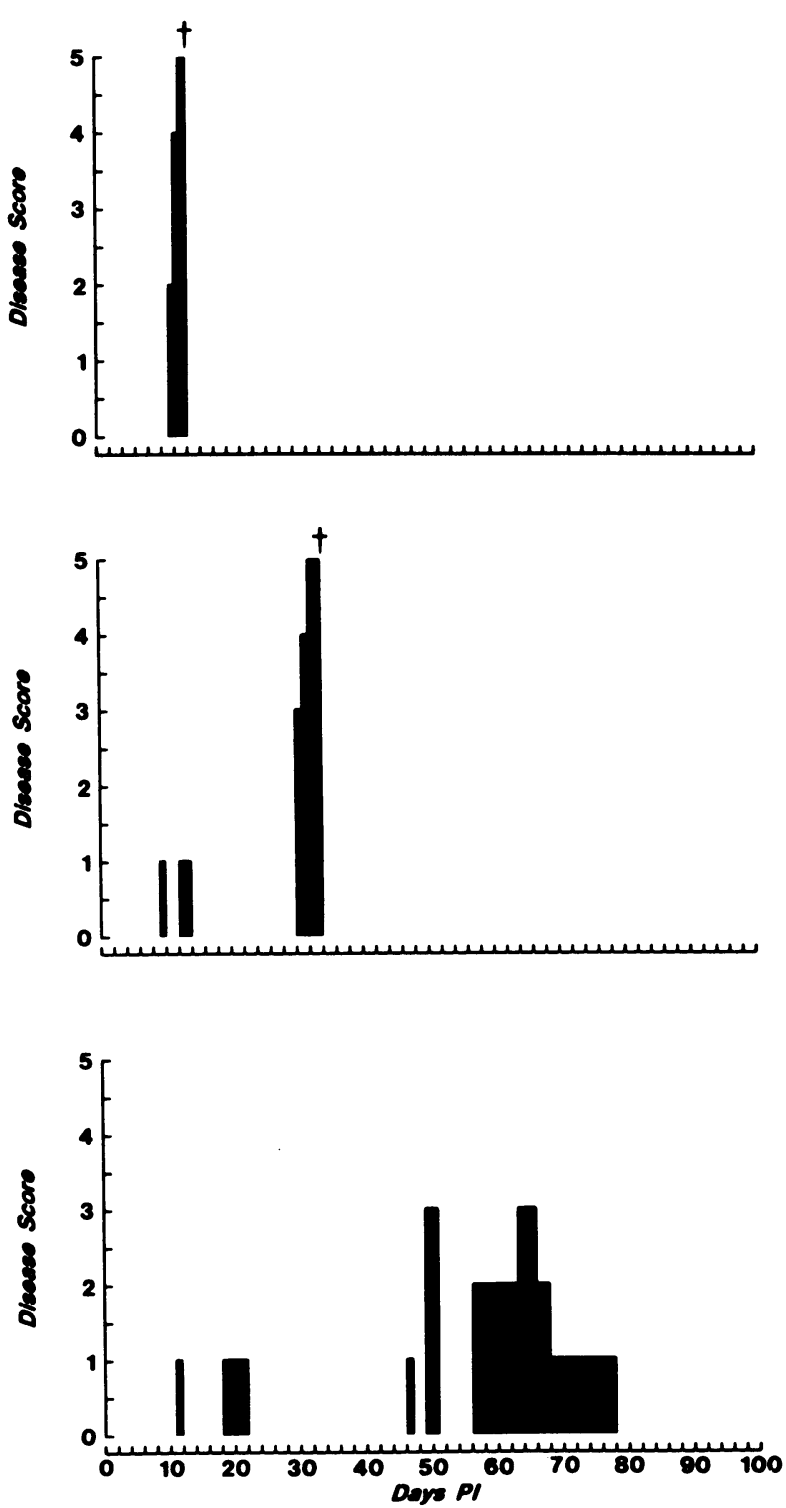

Figure 2. The clinical course of EAE in three cynomolgus monkeys immunized with the 14-mer MBP peptide before receiving a second immunization with BH. Preimmunization was accomplished using either CFA (middle panel) or Freund's adjuvant supplemented with muramyl dipeptide (top and bottom panels) as adjuvant. Clinical signs of EAE were present in all animals between 9 and $11 \mathrm{~d}$ postimmunization $(P I)$. For each animal, the clinical course $(y$-axis $)$ is illustrated for the time period after immunization with white matter homogenate $(x$-axis).

Table I summarizes PBMC responses to $\mathrm{BH}$ and MBP in relation to the onset of fatal and nonfatal attacks of EAE. The magnitude of the proliferative response to $\mathrm{BH}$ and MBP varied widely between animals. Immunization was associated with a fourfold increase in mitogen responsiveness and with the development of antigen-specific PBMC proliferative responses. A general correlation was observed between the magnitude of the response to $\mathrm{BH}$ and the severity of individual attacks: higher stimulation indexes tended to be associated with fatal outcome (Table I). No differences in the proliferative response to mitogens differentiated fatal from nonfatal attacks (not shown).
Quantitation of the circulating $T$ cell response. In six animals immunized with $\mathrm{BH} / \mathrm{CFA}$, the number of $\mathrm{T}$ cells specific to MBP were enumerated from peripheral blood by use of a soft agar colony system. The frequency of MBP-specific T cells could be estimated at between 5 and 20 per $10^{6}$ PBMC. As shown in Fig. 3, the number of MBP colonies and the kinetics of their appearance postimmunization in three individual animals correlated with the magnitude and kinetics of the proliferative response of whole PBMC to MBP.

In the three animals preimmunized with the MBP 156-169 peptide, peptide-specific colonies, enumerated on day 55 postimmunization, were estimated at 1,6 , and 9 per $10^{6}$ PBMC, respectively. PBMC proliferative responses to this peptide were generally low or undetectible, both in peptide-preimmunized animals (data not shown) and also in animals immunized only with BH/CFA (for example, Fig. 1, top right).

\section{Discussion}

The current report represents the first study of circulating antigen-specific $T$ cells in relapsing-remitting EAE. The large size of the animals and the chronic course provided the opportunity for serial phlebotomy and measurement of antigen reactivity during the course of the disease. Specific proliferative responses to $\mathrm{BH}$ and to MBP were present in all animals at the onset of clinical signs of EAE, and these responses persisted in surviving animals for the duration of study. Strong proliferative responses were associated with fatal attacks in most cases. Responses to PLP, a myelin protein capable of inducing EAE in some species (23), were generally undetectable or of lower magnitude than were those to $\mathrm{BH}$ or MBP.

In earlier studies of acute EAE in various species, PBMC responses to MBP were detected in some (24-27) but not in other (28) models. In the guinea pig, this response was transient and present only during the acute phase of disease (26). Current primate data, by contrast, indicate that antigen-reactive PBMC were present in all survivors of acute EAE, even for periods up to 10 mo postimmunization and long after the dissolution of a visible antigen depot. The persistence of these circulating cells may have contributed to the high relapse rate that occurred in this species.

A soft agar method for the enumeration of antigen-reactive $T$ cells permitted an estimate of the frequency of circulating MBP-reactive cells to be made. In acute EAE, between 5 and 20 per $10^{6}$ PBMC proliferated specifically to MBP. Unpublished data from our laboratory also indicate that a lower frequency of MBP-reactive T cells, estimated at 1 per $10^{6} \mathrm{PBMC}$, are present in clinically stable animals with chronic EAE studied 6-18 mo postimmunization. The true clonal frequency may be higher than these estimates, assuming limited sensitivity of the assay (particularly with respect to the $\mathrm{CD}^{+}$repertoire). On the other hand, only a fraction of $\mathrm{T}$ cells that proliferate to MBP in vitro are likely to be encephalitogenic in vivo (29). These considerations notwithstanding, it appears that, even during the course of acute fulminant EAE, few antigen-reactive cells are present in proliferation assays that typically employ $10^{5}$ to $10^{6}$ PBMC per well.

In humans with MS, small increases in PBMC responses to MBP are reported to distinguish patients from controls (1014). One recent estimate indicated that between 27 and 52 per $10^{6}$ PBMC were MBP-reactive as measured by MBP-induced 


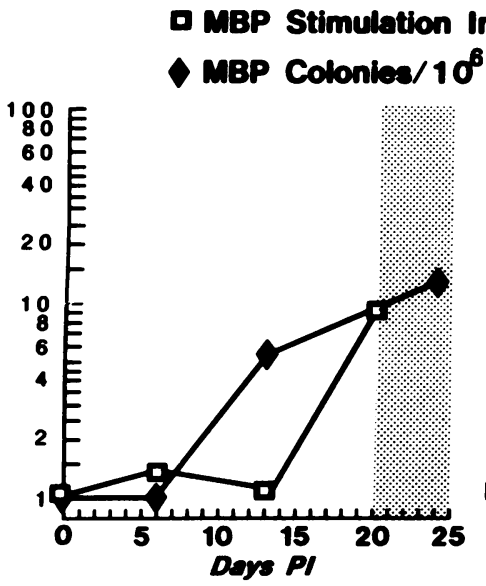

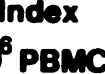
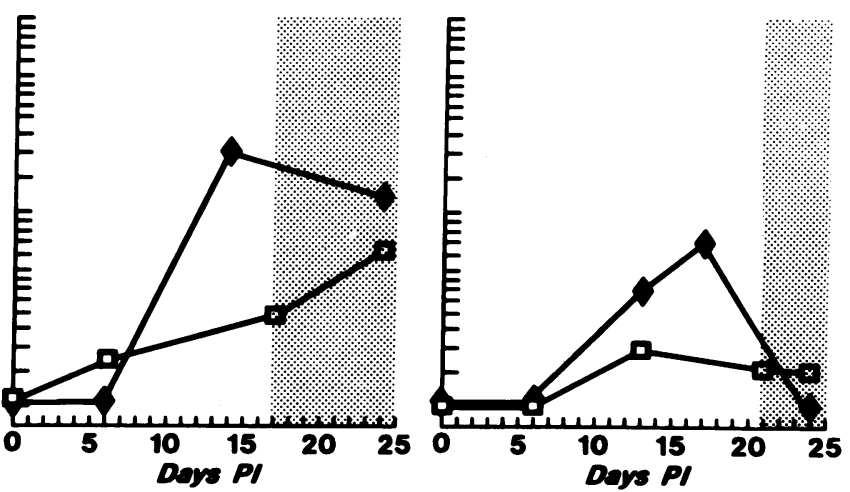

Figure 3. Correlation between the PBMC stimulation index and the frequency of MBP-specific T-cell colonies. Data from three immunized animals are shown. The stimulation index, or the number of colonies detected per $10^{6} \mathrm{PMBC}$, is displayed on the $y$-axis and the day postimmunization is shown on the $x$-axis. The shaded area represents the onset of clinical signs of EAE. See text for details.

interferon- $\gamma$ secretion (12). A lower estimate (1-5 per $10^{6}$ PBMC) was suggested in a second study of MBP precursors in PBMC of MS patients ( $H$. Offner and A. Vandenbar, personal communication). Thus, similar frequencies of circulating MBP-reactive cells may be present in both MS and EAE.

In the related species Rhesus (Macaca mulatta), EAE was induced by immunization with peptides corresponding to the carboxy-terminal region of MBP (30-33). In cynomolgus monkeys, we found that signs of EAE did not develop when a similar immunization regimen was employed, but that a markedly precocious onset of EAE followed subsequent immunization with BH/CFA-H37Ra. This suggests that peptide immunization may have sensitized the animals to EAE. It is surprising that the same region of MBP may play a role in inducing EAE in most if not all individuals belonging to two distinct (although closely related) primate species. In inbred rodents, the encephalitogenic $\mathrm{T}$ cell response to MBP has been shown to be strain and species specific, and to recognize restricted regions of MBP in the generation of an encephalitogenic response (reviewed in reference 34). In $\mathrm{H}-2^{\mathrm{u}}$ mice (B10.PL and PL/J), for example, the amino terminus of MBP is immunodominant for EAE, whereas in $\mathrm{H}-2^{\mathrm{s}}$ mice (SJL) the $89-101$ region is dominant. In nonhuman primates extensive polymorphism of major histocompatibility complex (MHC) gene products is present $(35,36)$ that might contribute to diversity in the response to MBP. Heterozygosity for MHC haplotypes in many individuals, coupled with additional MHC diversity resulting from interisotypy or transcomplementation, might broaden the potential for generation of $\mathrm{T}$ cell responses against multiple epitopes of a given antigen. In marmoset primates, for example, we have found that $\mathrm{T}$-cell lines responding to different regions of MBP can mediate passive transfer EAE (Massacesi et al., manuscript in preparation), and in MS patients no single region of MBP has been identified as immunodominant $(14,37$, 38). In macaques, sensitization to EAE by the carboxyterminal region of MBP suggests that effective presentation of epitopes within this peptide to $T$ cells is mediated by a variety of different MHC haplotypes.

In conclusion, relapsing-remitting EAE in cynomolgus monkeys is characterized by circulating $T$ cell responses to white matter antigens that persist over long periods of time and that broadly mirror the clinical illness. Furthermore, our data indicate that a chronic inflammatory disease in primates may result from relatively small increases in the circulating pool of cells responding to the target antigen. In rodents, intravenous passive transfer of as few as 30,000 cloned MBP-reactive T cells can produce EAE (39), demonstrating the remarkable efficiency of some encephalitogenic $T$ cell populations to mediate disease. Serial assessment of autoantigen-reactive $T$ cells from peripheral blood is thus a quantifiable immunologic marker of the disease process that can be easily applied to trials of therapy in EAE, and similar strategies may prove useful for monitoring of humans with MS or other T cell-mediated inflammatory diseases.

\section{Acknowledgments}

The authors thank Dr. Marjorie Lees, who kindly provided purified proteolipid apoprotein, and Drs. Richard Fisher and C. Ramachandra of Biogen, Inc. (Cambridge, MA), who synthesized the 14-mer peptide of MBP used in this study. The authors also wish to thank Leslie Hopper for technical assistance.

Luca Massacesi was a postdoctoral fellow of the Italian Multiple Sclerosis Society. Stephen L. Hauser is a Harry Weaver Neuroscience Scholar of the National Multiple Sclerosis Society (NMSS). This work was supported by grants from the NMSS, the Mathers Foundation, and the Rita Allen Foundation.

\section{References}

1. Pettinelli, D. B., and D. E. McFarlin. 1981. Adoptive transfer of experimental allergic encephalomyelitis in SJL/J mice after in vitro activation of lymph node cells by myelin basic protein: requirement for Lyt $1+2$ - T-lymphocytes. $J$. Immunol. 127:1420-1423.

2. Zamvil, S., P. Nelson, J. Trotter, D. Mitchell, R. Knobler, R. Fritz, and L. Steinman. 1985. T-cell clones specific for myelin basic protein induce chronic relapsing paralysis and demyelination. Nature (Lond.). 317:355-358.

3. McFarlin, D. E., S. E. Blank, and R. F. Kibler. 1974. Recurrent experimental allergic encephalomyelitis in the Lew rat. J. Immunol. 113:712.

4. Paterson, P. Y. 1982. Molecular and cellular determinants of neuroimmunologic inflammatory disease. Fed. Proc. 41:2569-2576.

5. Stohl, W., and N. K. Gonatas. 1978. Chronic permeability of the central nervous system to mononuclear cells in experimental allergic encephalomyelitis in the Lewis rat. J. Immunol. 120:844.

6. Goldmuntz, E. A., C. F. Brosnan, and W. T. Norton. 1986. Prazosin treatment suppresses increased vascular permeability in both acute and passively transferred experimental autoimmune encephalomyelitis in the lewis rat. J. Immunol. 137:3444-3450.

7. Traugott, U., and C. S. Raine. 1977. Experimental allergic encephalomyelitis in inbred pure guinea pigs: Correlation of disease in early T cells with clinical signs in suppressed and unsuppressed animals. 1977. Cell. Immunol. 34:146.

8. Traugott, U., S. H. Stone, and C. S. Raine. 1979. Chronic relapsing experimental allergic encephalomyelitis: correlation of circulating lymphocyte fluctuations with disease activity in suppressed and unsuppressed animals. $J$. Neurol. Sci. 41:17.

9. Raine, C. S. 1985. Experimental allergic encephalomyelitis and experimen- 
tal allergic neuritis. In Handbook of Clinical Neurology, Volume 3. Elsevier, Amsterdam. 429-466.

10. Johnson, D., D. A. Hafler, R. H. Quarles, M. Lees, R. O. Brady, R. H. Quarles, and H. L. Weiner. 1986. Cell mediated immunity to myelin-associated glyoprotein, proteolipid protein, and myelin basic protein in multiple sclerosis. $J$. Neuroimmunol. 13:99.

11. Selmaj, K., A. Nowak, and H. Tchorzewski. 1988. Multiple sclerosis: effect of myelin basic protein on interleukin 1, interleukin 2 production and interleukin 2 production and interleukin 2 receptor expression in vitro. Clin. Exp. Immunol. 72:428-433.

12. Olsson, T., W. Z. Wang, B. Hojeberg, V. Kostulas, Y-P-Jiang, G. Anderson, H. P. Ekre, and H. Link. 1990. Autoreactive T lymphocytes in multiple sclerosis determined by antigen-induced secretion of interferon. J. Clin. Invest. 86:981-985.

13. Allegretta, M., J. A. Nicklas, S. Sriram, and R. J. Albertini. 1990. T cells responsive to myelin basic protein in patients with multiple. Science (Wash. DC). 247:718-721.

14. Ota, K., M. Matsui, E. L. Milford, G. A. Mackin, H. L. Weiner, and D. A Hafler. 1990. T-cell recognition of an immunodominant myelin basic protein epitope in multiple sclerosis. Nature (Lond.). 346:183-187.

15. Rivers, T. M., D. M. Sprunt, and B. P. Berry. 1933. Observations on attempts to produce acute disseminated encephaloyelitis in monkeys. J. Exp. Med. 58:39.

16. Ferraro, A., and C. L. Cazzullo. 1948. Chronic experimental allergic encephalomyelitis in monkeys. J. Neuropathol. Exp. Neurol. 7:235-260.

17. Ravkina, L., V. Rogova, and L. Lazarenko. 1978. Chronic experimental allergic encephalomyelitis in rhesus monkeys and its modification by treatment J. Neurol. Sci. 38:281-293.

18. Alvord, E. C. Jr., C. M. Shaw, and S. Hruby. 1979. Myelin basic protein treatment of experimental allergic encephalomyelitis in monkeys. Ann. Neurol. 6:467-473.

19. Shaw, C. M., E. C. Alvord, Jr., and S. Hruby. 1988. Chronic remitting-relapsing experimental allergic encephalomyelitis induced in monkeys with homologous myelin basic protein. Ann. Neurol. 24:738-748.

20. Deibler, G. E., R. E. Martenson, and M. W. Kies. 1972. Large scale preparation of myelin basic protein in central nervous tissue of several mammalian species. Prep. Biochem. 2:139-165.

21. Lees, M. B., and J. D. Sakur. 1979. Preparation of proteolipids. In Research Methods in Neurochemistry. N. Marks and R. Rodnight, editors. Plenum Press, New York. 4:354-370.

22. Sredni, B., H. Y. Tse, and R. H. Schwartz. 1980. Direct cloning and extended cluture of antigen-specific MHC-restricted, proliferating $\mathrm{T}$ lymphocytes. Nature (Lond.). 283:581-583.

23. Tuohy, V. K., A. Lu, R. A. Sobel, R. A. Laursen, and M. B. Lees. 1989. Identification of an encephalitogenic determinant of myelin proteolipid protein for SJL mice. J. Immunol. 142:1523.

24. Fowler, I. 1972. In vitro responses of peripheral blood lymphocytes in experimental allergic encephalomyelitis. J. Immunol. 108:903-906.
25. Behan, P. O., M. W. Kies, R. P. Lisak, W. Sheremata, and J. B. Lamarche. 1973. Immunologic mechanisms in experimental encephalomyelitis in nonhuman primates. Arch. Neurol. 29:4-9.

26. Fallis, R. J., M. L. Powers, and Weiner H. L. 1987. Serial analysis of peripheral blood T-cell phenotypes and myelin basic protein reactivity in experimental allergic encephalo-myelitis. Neurology. 37:719-723.

27. Lyman, W. D., A. S. Kadish, and C. S. Raine. 1981. Experimental allergic encephalomyelitis in the guinea pig: variation in peripheral blood lymphocyte responsiveness to myelin basic protein during disease development. Cell. Im munol. 63:409-416.

28. Lisak, R. P., and B. Zweiman. 1974. In vitro and in vivo immune responses to homologous myelin basic protein in experimental allergic encephalomyelitis. Cell. Immunol. 11:212-220.

29. Zamvil, S. S., P. A. Nelson, D. J. Mitchell, R. L. Knobler, R. B. Fritz, and L. Steinman. 1985. Encephalitogenic $T$ cell clones specific for myelin basic protein: an unusual bias in antigen recognition. J. Exp. Med. 162:2107-2124.

30. Holtzman, E., A. R. Freeman, and L. A. Kashner. 1971. Biologic activity and synthesis of an encephalitogenic determinant. Science (Wash. DC) 173:736-738.

31. Kibler, R. F., P. K. Re, S. McKneally, and R. Shapira. 1972. Biological activity of an encephalitogenic fragment in the monkey. J. Biol. Chem. 969-972.

32. Eylar, E. H., S. Brostoff, J. Jackson, and H. Carter. 1972. Allergic encephalomyelitis in monkeys induced by a peptide from the A1 protein. Proc. Natl. Acad. Sci. USA. 69:617-619.

33. Karkhanis, Y. D., D. J. Carlo, S. W. Brostoff, and E. H. Eylar. 1975. Allergic encephalomyelitis. J. Biol. Chem. 5:1718-1722.

34. Seboun, E., N. Joshi, and S. L. Hauser. 1990. The biology of T-cell receptor genes and their role in demyelinating diseases. In Progress in Psychoneuroendocrinimmunology. R. M. McLeod, editor. Thieme Medical Publishers, Inc.,

35. Watkins, D. I., M. Kannagi, M. E., M. E. Stone, and N. L. Letvin. 1988. Major histocompatibility complex class 1 molecules of nonhuman primates. Eur. J. Immunol. 18:1425-1432.

36. Watkins, D. I., J. A. Shadduck, F. S. Hodl, M. E. Stone, N. L. Letvin. 1989. Use of cDNA probes specific for the human MHC class II beta loci for tissue-typing nonhuman primates at their class II beta loci. Transplantation (Baltimore). 47:172-173

37. Jingwu, A., J. C. Chi-Hsin, G. Hashim, R. Medar, and J. C. M. Raus. 1990. Preferential peptide specificity and HLA restriction of myelin basic protein-specific T cell clones derived from MS patients. Cell. Immunol. 129:189198.

38. Martin, R., D. Jaraquemada, M. Flerlage, J. Richert, J. Whitaker, E. O. Long, D. E. McFarlin, and H. F. McFarland. 1990. Fine specificity and HLA restriction of myelin basic protein specific cytotoxic $\mathrm{T}$ cell lines from multiple sclerosis patients and healthy individuals. J. Immunol. 145:540-548.

39. Vadenbark, A. A., T. Bill, and H. A. Offner. 1985. A myelin basic proteinspecific $\mathrm{T}$ lymphocyte line that mediates experimental autoimmune encephalomyelitis. J. Immunol. 135:223-228. 